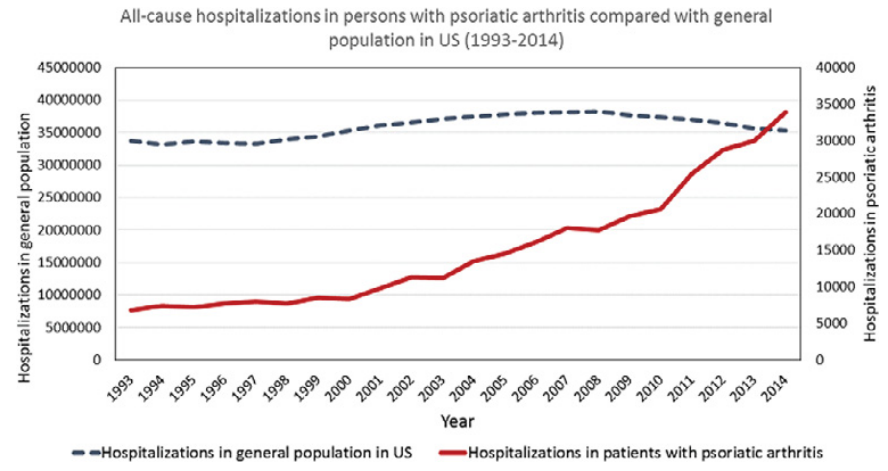

References:

[1] J Gelfand, D Gladman et al. Epidemiology of Psoriatic Arthritis in the Population of the United States. J Am Acad Dermatology, vol 53, p 573-577.

Disclosure of Interest: None declared

DOI: 10.1136/annrheumdis-2017-eular.5502

\section{FRI0489 CERTOLIZUMAB PEGOL IS ASSOCIATED WITH LONG-TERM IMPROVEMENTS IN PATIENT-REPORTED OUTCOMES IN PSORIATIC ARTHRITIS: 4-YEAR OUTCOMES FROM THE RAPID-PSA STUDY}

D. Gladman ${ }^{1}$, R. Fleischmann ${ }^{2}$, K. Harris ${ }^{3}$, L. Peterson ${ }^{4}$, P.J. Mease ${ }^{5}$.

${ }^{1}$ University of Toronto and Krembil Research Institute, Toronto Western Hospital, Toronto, Canada; ${ }^{2}$ UT Southwestern Medical Center and Dallas Metroplex Clinical Research Center, Dallas, United States; ${ }^{3}$ UCB Pharma, Brussels, Belgium; ${ }^{4}$ UCB Pharma, Raleigh; ${ }^{5}$ Swedish Medical Center and University of Washington, Seattle, United States

Background: Psoriatic arthritis (PSA) is a heterogeneous inflammatory disease that has a substantial impact on patients' (pts) physical and emotional wellbeing. ${ }^{1}$ Certolizumab pegol (CZP) is an Fc-free, PEGylated anti-TNF that has been shown to improve patient-reported outcomes (PROs) in pts with PsA over 96 weeks (wks) of treatment in the RAPID-PsA study (NCT01087788). ${ }^{2}$

Objectives: To investigate whether initial improvements in PROs observed with CZP treatment were maintained over 4 years in the RAPID-PsA study.

Methods: RAPID-PsA was double-blind and placebo-controlled to Wk24, doseblind to Wk48, and open-label to Wk216. Pts were aged $>18$ years, with a diagnosis of active PsA, and had failed treatment with $\geq 1$ DMARD. Pts originally randomized to CZP (400mg at Wks0,2,4 [loading dose] followed by either $200 \mathrm{mg}$ every 2 wks [Q2W] or $400 \mathrm{mg}$ every 4 wks [Q4W]) continued on their assigned dose during the open-label period. PROs assessed included Patient's Global Assessment of Arthritis Pain (PtAAP; visual analog scale), fatigue (numeric rating scale), Health Assessment Questionnaire-Disability Index (HAQ-DI), Short Form-36 Physical and Mental Component Summary (SF-36 PCS/MCS), Psoriatic Arthritis Quality of Life (PsAQoL), and Dermatology Life Quality Index (DLQI; assessed in the subgroup of pts with $\geq 3 \%$ body surface area affected by psoriasis at baseline [BL]). Data are reported as the mean change from BL (CFB) for pts randomized to CZP at WkO, with last observation carried forward (LOCF) imputation for Wk24, and LOCF imputation and observed case (OC) values for Wk216.

Results: Of 273 pts randomized to CZP at Wk0, $248(91 \%)$ completed Wk24 and $183(67 \%)$ completed Wk216. Improvements observed to Wk24 of treatment were generally maintained over 4 years (to Wk216) in all PROs assessed, regardless of prior anti-TNF exposure (Table). Similar improvements were observed in both CZP dose regimens for all PROs examined, including PtAAP (CFB at Wk216 in the 200mg Q2W group [with LOCF imputation]: -30.5, in the 400mg Q4W group: -33.8); fatigue (-2.3, -2.3); HAQ-DI (-0.50, -0.49); SF-36 PCS (8.73, 8.77); SF-36 MCS (3.91, 3.28); PsAQoL (-4.6, -4.4); and DLQI (-8.4, -6.8).

Conclusions: Early improvements with CZP treatment were maintained over 4 years in all PROs assessed in the RAPID-PsA study. Similar improvements were observed in pts with and without prior anti-TNF exposure, and in both CZP dose regimens.

References:

[1] Rosen C. Rheumatology 2012;51(3):571-6.

[2] Gladman D. Value in Health 2014;17(7):A386.

Acknowledgements: This study was funded by UCB Pharma. We thank the patients and their caregivers in addition to the investigators and their teams who contributed to this study. Editorial services were provided by Costello Medical Consulting.

Disclosure of Interest: D. Gladman Grant/research support from: Abbott, BristolMyers Squibb, Celgene, Johnson \& Johnson, MSD, Novartis, Pfizer, UCB Pharma, Consultant for: Abbott, Bristol-Myers Squibb, Celgene, Johnson \& Johnson, MSD, Novartis, Pfizer, UCB Pharma, R. Fleischmann Grant/research support from: Genentech Inc, Roche, Abbott, Amgen, UCB Pharma, Pfizer, Bristol-Myers Squibb, Lilly, Sanofi-Aventis, MSD, Novartis, AstraZeneca, Janssen, Consultant for: Roche, Abbott, Amgen, UCB Pharma, Pfizer, Bristol-Myers Squibb, Lilly,
Table: Mean change from baseline in patient-reported outcomes at Weeks 24 and 216 in patients with or without prior anti-TNF exposure

\begin{tabular}{|c|c|c|c|c|c|c|c|c|c|}
\hline & \multicolumn{3}{|c|}{$\begin{array}{l}\text { Patients with prior } \\
\text { anti-TNF exposure } \\
\text { CZP dose oombined } \\
(n=54)\end{array}$} & \multicolumn{3}{|c|}{$\begin{array}{c}\text { Patients without prior } \\
\text { anti-TNF exposure } \\
\text { CZP dose oombined } \\
(n=219)\end{array}$} & \multicolumn{3}{|c|}{$\begin{array}{c}\text { Overall } \\
\text { CZP dose combined } \\
\text { (N=273) }\end{array}$} \\
\hline & $\begin{array}{l}\text { Wk24 } \\
\text { (LOCF) }\end{array}$ & $\begin{array}{l}\text { Wk216 } \\
\text { (LOCF) }\end{array}$ & $\begin{array}{l}\text { Wk216 } \\
(\mathrm{OC}) \\
{[\mathrm{n}=34]}\end{array}$ & $\begin{array}{l}\text { Wk24 } \\
\text { (LOCF) }\end{array}$ & $\begin{array}{l}\text { Wk216 } \\
\text { (LOCF) }\end{array}$ & $\begin{array}{l}\text { Wk216 } \\
\text { (OC) } \\
{[n=151]}\end{array}$ & $\begin{array}{l}\text { Wk24 } \\
\text { (LOCF) }\end{array}$ & $\begin{array}{l}\text { Wk216 } \\
\text { (LOCF) }\end{array}$ & $\begin{array}{c}\text { Wk216 } \\
\text { (OC) } \\
{[n=185]}\end{array}$ \\
\hline \multicolumn{10}{|l|}{ Outcome } \\
\hline Pain (PtAAP) [a] & -33.3 & -34.6 & -44.2 & -27.3 & -31.5 & -35.9 & -28.5 & -32.1 & -37.4 \\
\hline Fatigue [b] & -2.1 & -2.0 & -2.5 & -2.0 & -2.3 & $\begin{array}{c}-2.8 \\
{[n=147]}\end{array}$ & -2.0 & -2.3 & $\begin{array}{c}-2.7 \\
{[n=181]}\end{array}$ \\
\hline HAQ-DI [o] & -0.60 & -0.59 & -0.67 & -0.45 & -0.47 & -0.54 & -0.48 & -0.50 & -0.57 \\
\hline SF-36 PCS [d] & 8.37 & 9.79 & $\begin{array}{c}11.18 \\
{[n=33]}\end{array}$ & 7.92 & 8.50 & $\begin{array}{c}9.64 \\
{[n=148]}\end{array}$ & 8.01 & 8.75 & $\begin{array}{c}9.92 \\
{[n=181]}\end{array}$ \\
\hline SF-36 MCS $[e]$ & 4.57 & 2.38 & $\begin{array}{c}5.29 \\
{[n=33]}\end{array}$ & 4.49 & 3.90 & $\begin{array}{c}5.36 \\
{[n=148]}\end{array}$ & 4.50 & 3.60 & $\begin{array}{c}5.35 \\
{[n=181]}\end{array}$ \\
\hline$P \frown A Q \circ L[f]$ & -4.1 & -4.2 & -5.1 & -3.8 & -4.6 & $\begin{array}{c}-5.1 \\
{[n=150]}\end{array}$ & -3.9 & -4.5 & $\begin{array}{c}-5.1 \\
{[n=184]}\end{array}$ \\
\hline DLQI [g] & $\begin{array}{c}-9.0 \\
{[n=36]}\end{array}$ & $\begin{array}{c}-8.1 \\
{[n=36]}\end{array}$ & $\begin{array}{c}-10.9 \\
{[\mathrm{n}=20]}\end{array}$ & $\begin{array}{c}-7.2 \\
{[n=130]}\end{array}$ & $\begin{array}{c}-7.5 \\
{[n=130]}\end{array}$ & $\begin{array}{c}-7.9 \\
{[n=87]}\end{array}$ & $\begin{array}{c}-7.6 \\
{[n=166]}\end{array}$ & $\begin{array}{c}-7.6 \\
{[n=166]}\end{array}$ & $\begin{array}{c}-6.4 \\
{[n=180]}\end{array}$ \\
\hline
\end{tabular}

[a] Range: $0-100$, where $0=$ no pain and $100=$ worst pain (Minimal Clinically Important Difference [MCID]: -10 ); [b] Range: $0-10$, where $0=$ no fatigue and $10=$ worst fatigue (MCID: -1$)$; [c] Range: $0-3$, where $0=$ no disability and $3=$ very severe disability (MCID: -0.3 ); [d] Range: $1-81$, where higher scores indicate better physical status (MCID: +2.5); [e] Range: -9-82, where higher scores indicate better mental status (MCID:+2.5);

[f] Range: $0-20$, where lower scores indicate better quality of life; [g] Range: $0-30$, where lower scores

indicate better quality of life (MCID: -5). LOCF: last observation carried forward; OC: observed case.

Sanofi-Aventis, Novartis, AstraZeneca, Janssen, K. Harris Employee of: UCB Pharma, L. Peterson Employee of: UCB Pharma, P. Mease Grant/research support from: (Abbott) AbbVie, Amgen, Bristol-Myers Squibb, Celgene, Janssen, Lilly, Novartis, Pfizer, Sun, UCB Pharma, Consultant for: (Abbott) AbbVie, Amgen, Bristol-Myers Squibb, Celgene, Crescendo, Corrona, Dermira, Janssen, Lilly, Merck, Novartis, Pfizer, Sun, UCB Pharma, Zynerba, Speakers bureau: (Abbott) AbbVie, Amgen, Bristol-Myers Squibb, Celgene, Crescendo, Genentech, Janssen, Novartis, Pfizer, UCB Pharma

DOI: 10.1136/annrheumdis-2017-eular.1654

\section{FRI0490 REAL-LIFE EFFECTIVENESS OF TNF INHIBITORS IN PSORIATIC ARTHRITIS: ARE CHANGING NATIONAL POLICIES ON CHOICE OF TNF INHIBITOR REFLECTED IN RESPONSE TO TREATMENT?}

E.K. Kristianslund ${ }^{1}$, K.M. Fagerli ${ }^{1}$, E. Lie ${ }^{1}$, A. Wierød ${ }^{2}$, S. Kalstad ${ }^{3}$, E. Rødevand ${ }^{4}$, F. Krøl| ${ }^{5}$, P. Mielnik ${ }^{6}$, T.K. Kvien ${ }^{1}$, I.C. Olsen ${ }^{1} .{ }^{1}$ Department of Rheumatology, Diakonhjemmet Hospital, Oslo; ${ }^{2}$ Department of Rheumatology, Drammen Hospital, Drammen; ${ }^{3}$ Department of Rheumatology, University Hospital of North Norway, Tromsø: ${ }^{4}$ Department of Rheumatology, St. Olavs Hospital, Trondheim; ${ }^{5}$ Revmatismesykehuset, Lillehammer; ${ }^{6}$ Department of Rheumatology, Førde Central Hospital, Førde, Norway

Background: Tumour necrosis factor inhibitors (TNFi) are essential in the treatment of psoriatic arthritis (PsA). Whether the effectiveness of the five different TNFi differs is not known, as they have not been directly compared. In Norway the national authorities consider the TNFi to be equivalent, and since 2009 the least expensive drug in an annual national tender has been preferred in the publicly funded healthcare system. This has led to substantial year-to-year differences in chioce of first TNFi, the system has acted as an unbiased factor distributing patients between different agents across years.

Objectives: Comparing response to TNFi during the first year of treatment of PsA over years with highly varying uptake of different TNFi.

Methods: From the NOR-DMARD register we included the 715 biologics-naïve patients with PsA who started their first TNFi from 2009 through 2015. The preferred TNFi in national recommendations were: 2009 adalimumab, 2010 golimumab, 2011 and 2012 etanercept, 2013 golimumab, 2014 certolizumab, 2015 certolizumab/biosimilar infliximab (CT-P13). The estimated Disease Activity Score 28 joints (DAS28) at 3, 6 and 12 months after treatment start was compared between treatment years using a mixed-model, adjusted for baseline disease activity, age, sex and treatment centre.

Results: Demographics, choice of TNFi and baseline characteristics are listed for each year 2009-2015 in Table 1. The preferred drug was started in 56-91\% of patients. There was a trend towards lower disease activity at baseline over time. There were no significant differences in DAS28 at 3 and 6 months between treatment years, but a difference was found at 1 year (figure).

Conclusions: The results from this innovative analytic approach indicate similar effectiveness of different TNFi in PsA, and consequently supports the practice of selecting agent based on cost and feasibility of use. However, there are potential differences after 1 year. The interpretation of this is challenging, especially as there is a marked difference in outcomes between the years 2011 and 2012, where the distribution of type of TNFi was similar. 